\title{
Operation Windows of the Oxygen Blast Furnace with Top Gas Recycling
}

\author{
Mikko HELLE* and Henrik SAXÉN \\ Thermal and Flow Engineering, Faculty of Science and Engineering, Åbo Akademi University, Åbo, Fl-20500 Finland. \\ (Received on February 10, 2015; accepted on June 15, 2015; J-STAGE Advance published date: August \\ $28,2015)$
}

\begin{abstract}
Due to global concern about climate change, efforts in the steel industry to decrease emissions must be introduced, as this industrial sector gives rise to $5-7 \%$ of the anthropogenic $\mathrm{CO}_{2}$ emissions. There are several possibilities to achieve this goal: Making the processes more energy efficient, changing to renewable energy sources, by introducing process modifications or completely new processes, etc. In this paper the concept of oxygen blast furnace, where pure oxygen is used as blast combined with recycling of $\mathrm{CO}_{2}-$ stripped top gas, is studied numerically. In the analysis, special attention is paid to the amount of recycled top gas and how the gas should be divided between injection to the lower (hearth) and upper (shaft) tuyeres. The results shed light on the feasible operation window, under the given process constraints, for the oxygen blast furnace and also how different combinations of hearth and shaft gas injections are reflected in coke rate, oxygen rate and top gas composition, as well as in the emissions. The issue whether the recycled top gas must be heated in regenerative heat exchanges is also addressed by considering the alternative where the recycled gas to the lower tuyeres is injected cold, while the shaft gas is elevated to the reserve zone temperature by partial combustion. The findings of the study are expected to be useful for assessing the feasibility of operating the blast furnace under high top gas recycling rates.
\end{abstract}

KEY WORDS: oxygen blast furnace; operation regime; recycle gas preheating; hearth and shaft injection.

\section{Introduction}

Global warming due to the rising $\mathrm{CO}_{2}$ levels in the atmosphere is seen as one of the biggest threats for mankind in the future. The steel industry contributes by $5-7 \%$ of the anthropogenic $\mathrm{CO}_{2}$ emissions in the world and is therefore searching new ways to decrease the emissions considerably. The oxygen blast furnace (OBF) is considered one of the most promising concepts for this difficult task. ${ }^{1)}$ In the OBF oxygen is used instead of air as blast, and the top gas is recycled, after $\mathrm{CO}_{2}$ removal, either to the lower tuyeres or to tuyeres in the shaft, or to both. If the removed $\mathrm{CO}_{2}$ is not released to the atmosphere, this concept can significantly reduce the emissions. In $1984 \mathrm{Lu}$ and $\mathrm{Kumar}^{2)}$ studied the feasibility of the nitrogen-free blast furnace, with top gas recycling to tuyeres, natural gas injection and plasma torch. The calculation predicted a $1 / 3$ increase in the production rate and savings of 100-200 kg/t $\mathrm{hm}$ of coke. Qin and Yang ${ }^{3)}$ studied a top gas recycling concept with massive coal injection. Calculations were made both with high oxygen enrichment of the blast and pure oxygen. The recycled top gas was injected to the shaft after $\mathrm{CO}_{2}$ and $\mathrm{H}_{2} \mathrm{O}$ removal. The calculations estimated a $380 \mathrm{~kg} / \mathrm{t}_{\mathrm{hm}}$ fuel rate, when pure oxygen and $240 \mathrm{~kg} / \mathrm{t}_{\mathrm{hm}}$ coal is used; this corresponds to a

\footnotetext{
* Corresponding author: E-mail: mihelle@abo.fi

DOI: http://dx.doi.org/10.2355/isijinternational.ISIJINT-2015-083
}

$120 \mathrm{~kg} / \mathrm{t}_{\mathrm{hm}}$ decrease in fuel rate compared to a conventional BF operation with only coke $\left(500 \mathrm{~kg} / \mathrm{t}_{\mathrm{hm}}\right)$. Ohno et al. ${ }^{4)}$ used mathematical models and operation tests to study a concept where cold oxygen with pulverized coal was injected through tuyeres and hot preheating gas to the shaft. It should be noted that no hot stoves were needed in this concept.

Top gas recycling blast furnace trials have been made already in the 1980's in Russia, ${ }^{5)}$ where the recycled top gas was injected back to the blast furnace through tuyeres after $\mathrm{CO}_{2}$ removal and reheating. Results showed a decrease of $28-30 \%$ in the carbon input as $1100 \mathrm{Nm}^{3} / \mathrm{t}_{\mathrm{hm}}$ hot reducing gas was injected together with $250 \mathrm{Nm}^{3} / \mathrm{t}_{\mathrm{hm}}$ oxygen blast $\left(87 \% \mathrm{O}_{2}\right)$. Trials were also made more recently as part of the ULCOS research program. ${ }^{1,6)}$ In these trials three different versions (V1, V3 and V4) of top gas recycling were tested in practice, where $\mathrm{CO}_{2}$ removal of the recycled gas was the first step in all version and pure cold oxygen was injected through the hearth tuyeres: Preheated recycled top gas injected through the conventional hearth tuyeres (V3), preheated recycled gas injected through both shaft and hearth tuyeres (V4), and preheated recycled gas injected through shaft tuyeres and cold recycled gas through hearth tuyeres. All the tested cases showed savings in the coke and coal input and the best results were obtained with V3 and V4.

Mathematical models and simulations of top gas recycling blast furnace have been reported by many authors. Austin et $a l^{7)}$ estimated a $20 \%$ decrease in the fuel rate 
compared to normal blast furnace operation when hot reducing gas was injected. Murai et al. ${ }^{8)}$ studied shaft gas injection and reported a decrease in the reduction agent rate (RAR) of $34 \%$, when simultaneously $250 \mathrm{~kg} / \mathrm{t}_{\mathrm{hm}}$ of PCI was replaced with $100 \mathrm{~kg} / \mathrm{t}_{\mathrm{hm}}$ waste plastics. Nogami et al. ${ }^{9)}$ compared standard blast furnace operation with coal injection $\left(205 \mathrm{~kg} / \mathrm{t}_{\mathrm{hm}}\right)$ against standard operation with plastics injection and top gas recycling with plastics injection. In the studied case $37 \%$ of the top gas was recycled and injected cold together with cold oxygen. This lead to a $5 \%$ increase in the RAR. Recently, Sahu et al. ${ }^{10)}$ studied the integration of top gas recycling blast furnace to an integrated steel plant. Cases were studied with blast oxygen content ranging up to $100 \%$. For full oxygen blast, $86 \%$ top gas recycle and $200 \mathrm{~kg} / \mathrm{t}_{\mathrm{hm}}$ pulverized coal injection the coke rate was calculated to decrease to $235 \mathrm{~kg} / \mathrm{t}_{\mathrm{hm}}$.

In most investigations reported in the literature, only a few points of operation have been studied, but the ground why these specific points were selected has not been reported. Even for conventional blast furnace operation, very few papers have treated the feasible region of operation and how the constraints affect the admissible states of the furnace. ${ }^{11-13)}$ This is a motivation for the work reported in the present paper. The next section describes the problem formulation, followed by Section 3 which presents some results on the feasible operation window of the oxygen blast furnace with top gas recycling for two different concepts of gas recycling. The last and fourth section presents some conclusions.

\section{Problem Formulation}

The core of the studied system is a mathematical model of the blast furnace ${ }^{13)}$ based on the treatment by Rist and co-workers. ${ }^{14)}$ In addition to a raceway model, it is based on the division of the process into two control volumes, an upper preparation zone and a lower elaboration zone, separated by reserve zone where the temperatures of solids and gas are known and the gas composition can be calculated. The base model of the furnace, which has been extended to consider top gas recycling after $\mathrm{CO}_{2}$ stripping, is described in detail by Helle et al., ${ }^{15)}$ and also in Refs. 16), 17) where the recycled amount of top gas was optimized with respect to economic and environmental criteria. For the case of simplicity, the stripping unit is considered to remove $95 \%$ of the $\mathrm{CO}_{2}$ while the remaining gas components were taken to pass unaffected through the unit. To be able to also study shaft injection of the recycled top gas, the model was modified to allow for injecting recycled gas into the reserve zone at the reserve zone temperature. The solution procedure described by Helle et al. $^{15)}$ was modified by calculating a new gas composition in the reserve zone after the shaft injection, i.e., a new composition of the gas entering the preparation zone. This composition is related to the equilibrium composition by an approach, called the shaft efficiency parameter. In the base case the shaft efficiency was taken to be $\mathrm{SE}=90 \%$, and the reserve zone was characterized by a temperature of $920^{\circ} \mathrm{C}$. Since the arising nonlinear equations of the model are solved for iteratively, the introduction of shaft injection into the model constituted no major complication for the solution procedure. The Appendix provides a brief presenta- tion of the model.

Figure 1 depicts the cases studied in the work. In Case 1 the recycled and $\mathrm{CO}_{2}$-stripped top gas is heated in the hot stoves to the blast temperature and injected to the upper and/ or lower tuyeres. The gas injected in the shaft is cooled to the reserve zone temperature by mixing it with cold recycled gas. In Case 2 the recycled top gas in injected cold in the lower tuyeres and the share that is injected into the shaft is partially combusted to reach the reserve zone temperature. This solution is interesting as it needs no preheating of the gas but only a chamber for partial combustion.

The system was solved by discretizing the amount of recycled top gas and the share of it that goes into shaft injection. For each point the resulting equation system was solved numerically in Matlab by minimizing the coke rate. Thus, the results represent optimal solutions in terms of external reductants, as the injection of pulverized coal was fixed. The blast furnace was operated at a constant production rate $170 \mathrm{t}_{\mathrm{hm}} / \mathrm{h}$ with $100 \%$ pellet burden and some limestone and/or quartzite to adjust the slag rate to be at least $150 \mathrm{~kg} / \mathrm{t}_{\mathrm{hm}}$ and the basicity to ensure sufficient sulfur removal from the hot metal. Pulverized coal injection was kept fixed at $150 \mathrm{~kg} / \mathrm{t}_{\mathrm{hm}}$, and $\mathrm{N}_{2}$ was used as carrier gas. The recycled top gas was heated to $1200^{\circ} \mathrm{C}$ with primarily the blast furnace top gas and if there is not enough top gas available, then adding a sufficient amount of coke oven gas. The reserve zone temperature was assumed to be $920^{\circ} \mathrm{C}$.

\section{Results}

\subsection{Illustrations}

The results of the study are next depicted in figures, with twelve subpanels showing the flame temperature, top gas temperature, coke rate, specific oxygen consumption, specific export gas energy, bosh gas volume, solid residence time, share of recycled top gas $(\beta)$, the change in the specific $\mathrm{CO}_{2}$ emissions (with respect to the reference state) and the composition of the dry top gas $\left(\mathrm{CO}, \mathrm{CO}_{2}\right.$ and $\left.\mathrm{H}_{2}\right)$ as functions of the specific volume flow rate of injected recycled gas $\left(\dot{V}_{\mathrm{rg}}\right)$ and the share of recycled gas injected in the shaft $(\gamma)$. Observe that $\beta$ defines the share of top gas recycled, $\dot{V}_{\text {rg }}$ is the recycled gas after $\mathrm{CO}_{2}$ stripping and $\gamma$ defines the share of this gas that is injected into the shaft. To exemplify, if the furnace produces $1200 \mathrm{Nm}^{3} / \mathrm{t}_{\mathrm{hm}}$ top gas and $\beta=0.8$,

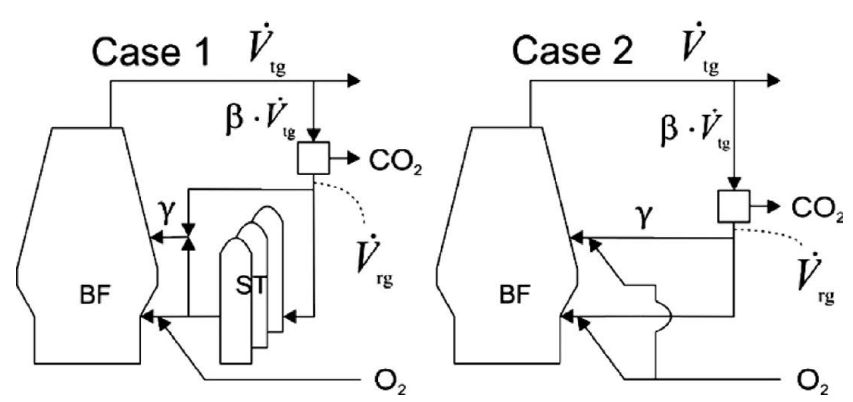

Fig. 1. Case 1: Recycled top gas heated in the stoves and injected either in the lower tuyeres or to the shaft. Case 2: Recycled top gas injected cold in the lower tuyeres and the share injected in the shaft is heated by partial combustion. The share of the recycled gas that is injected in the shaft is denoted by $\gamma$. 
$\gamma=0.4$, then $80 \%$ of the top gas $\left(960 \mathrm{Nm}^{3} / \mathrm{t}_{\mathrm{hm}}\right)$ is passed to $\mathrm{CO}_{2}$ removal. If, say, $360 \mathrm{Nm}^{3} / \mathrm{t}_{\mathrm{hm}} \mathrm{CO}_{2}$ is removed, this gives $\dot{V}_{\mathrm{rg}}=600 \mathrm{Nm}^{3} / \mathrm{t}_{\mathrm{hm}}$, so $240 \mathrm{Nm}^{3} / \mathrm{t}_{\mathrm{hm}}$ is injected into the shaft while the rest $\left(360 \mathrm{Nm}^{3} / \mathrm{t}_{\mathrm{hm}}\right)$ goes to the hearth tuyeres. Also note that the export gas energy can be positive (if there is an excess of top gas) or negative (if the top gas is insufficient and also coke oven gas is needed for the heating in the stoves). The change in the specific emissions of the blast furnace from the reference state (normal operation at a PCI rate of $150 \mathrm{~kg} / \mathrm{t}_{\mathrm{hm}}$ ) were estimated based on fixed emission factors for coke and oil, where the latter fuel was selected to compensate for the decrease in the energy of the export gas used in the downstream processes. It should be noted that the reduction in the $\mathrm{CO}_{2}$ emissions caused by a storage of the separated $\mathrm{CO}_{2}$ is not considered in the reported value; this will, however, be treated in subsection 3.3.

These twelve variables are depicted by contours in the subfigures. The shaded area in the figures depicts the operation window that does not violate the constraints imposed, i.e., it shows the feasible operation region. In all cases the constrains were the same: Flame temperature:

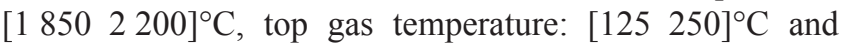
bosh gas volume: $\left[\begin{array}{ll}150 & 250\end{array}\right] \mathrm{kNm}^{3} / \mathrm{h}$. A low value of the lower limit of the flame temperature was selected on the basis of experiences reported at blast furnace injecting gases with high hydrogen content, e.g., coke oven gas. ${ }^{18)}$ However, it should be noted that the selected limits are indicative only, and that the operation window may be redefined according to other values as the figures hold contours for the variables studied. For easier reference to the corners of the feasible region in the results to be presented, Fig. 2 introduces a notation with the symbols $*, \square, \diamond, \bigcirc$ for the corner coordinates moving clock-wise through them. Finally, a noteworthy matter in analyzing the results is that the states of the operation window may change even though the location of the feasible region seems unaffected, because the twelve variables depicted by contours show changes.

\subsection{Case 1}

This subsection presents results for Case 1, i.e., where the recycled gas is heated in the stoves.

\subsubsection{Base Example, Blast Temperature $1200^{\circ} \mathrm{C}$}

Figure 3 illustrates the results for a base example for Case 1, where the "blast" temperature, i.e., the temperature of the hot reducing gas, is $1200^{\circ} \mathrm{C}$, while the shaft gas temperature is lowered to $920^{\circ} \mathrm{C}$ using bypassing (cf. Fig. 1). It can be seen that the limits of the operation window are set by the flame temperature and the top gas temperature constraints. The allowable specific top gas recycling rate is approximately in the range $600-800 \mathrm{Nm}^{3} / \mathrm{t}_{\mathrm{hm}}$ (between $\bigcirc$ and $\square$ ), the share of shaft gas varies between $0 \%$ and $48 \%$ (between points $*$ and $\diamond$ ), and the extreme values coincide with the extreme values of the specific recycled gas rate. The coke rate is low and varies in the range $230-280 \mathrm{~kg} / \mathrm{t}_{\mathrm{hm}}$, where the lowest value (at point ${ }^{*}$ ) is obtained for recycled gas injection $\left(620 \mathrm{Nm}^{3} / \mathrm{t}_{\mathrm{hm}}\right)$ through the lower tuyeres only. In this point, the flame temperature and the top gas temperature are at their lower bounds. Interestingly, following the

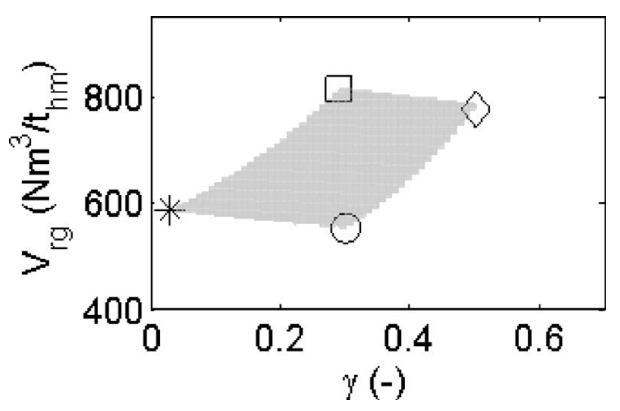

Fig. 2. Symbols used in the analysis of the results figures to denote the different vertices of the operation window.
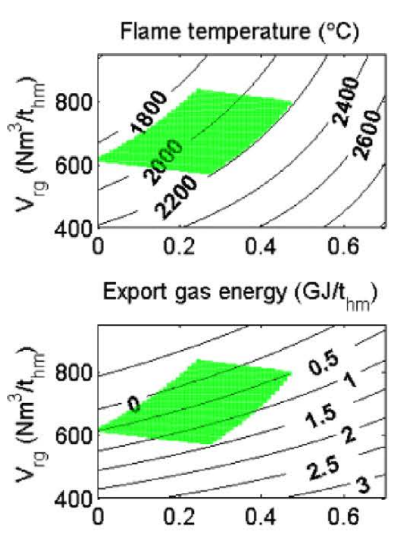

$\Delta \mathrm{CO}_{2}(\mathrm{~kg} / \mathrm{thm})$

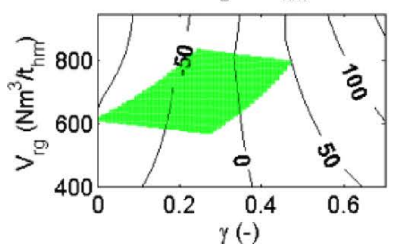

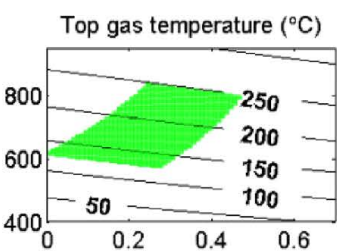
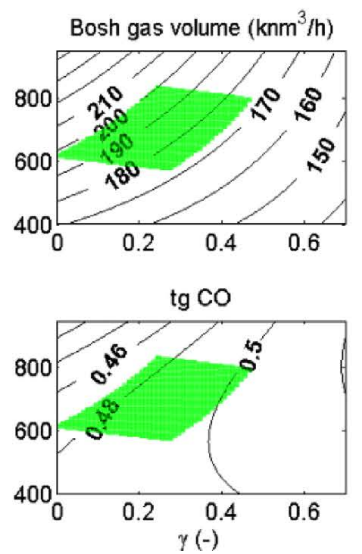
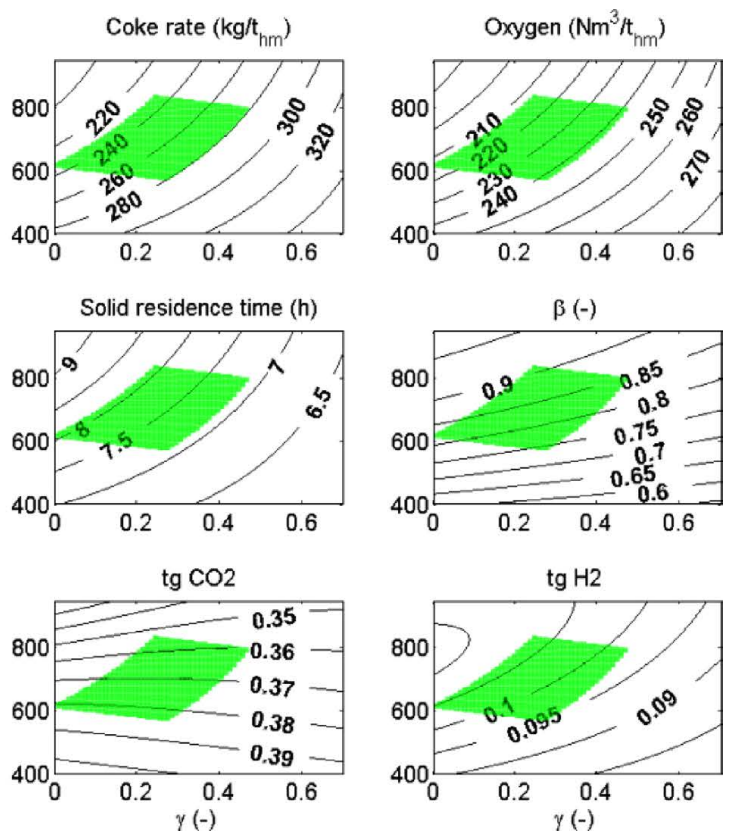

Fig. 3. Case 1: Blast temperature of $1200^{\circ} \mathrm{C}$ and PCI rate of $150 \mathrm{~kg} / \mathrm{t}_{\mathrm{hm}}$. Variables in the title of each subfigure depicted as functions of the share of shaft gas $(\gamma)$ and the specific injected top gas rate. The shaded (green) area shows the feasible operation window. (Online version in color.) 
lower bound of the flame temperature from point * to point $\square$, practically the same coke rate can be obtained when the share of shaft gas injection is increased simultaneously with an increase in the rate of recycled gas. Further scrutiny of the conditions along this line reveals that the shaft gas increases as much as the total recycled gas, so the rate of gas injected into the lower tuyeres is constant, which explains why the flame temperature remains constant. It should be noted that the maximum coke saving with this concept is about $100 \mathrm{~kg} / \mathrm{t}_{\mathrm{hm}}$, since the coke rate for the reference furnace without top gas recycling is $333 \mathrm{~kg} / \mathrm{t}_{\mathrm{hm}}$ (at a pulverized coal rate of $150 \mathrm{~kg} / \mathrm{t}_{\mathrm{hm}}$ ). This coke saving compares favorably with the values $70-90 \mathrm{~kg} / \mathrm{t}_{\mathrm{hm}}$ at a gas injection rate of of $600-800 \mathrm{Nm}^{3} / \mathrm{th}_{\mathrm{hm}}$ reported by Hirsch et al. in the ULCOS project. ${ }^{19)}$

The specific oxygen consumption varies in the range $212-242 \mathrm{Nm}^{3} / \mathrm{t}_{\mathrm{hm}}$, where the highest rates, quite naturally, correspond to the highest rates of injected gas. However, the highest share of top gas recycling, $\beta>0.9$, is encountered at the point $\square$, where the flame temperature is at its minimum and the top gas temperature at its maximum. At this point, the top gas $\mathrm{N}_{2}$ content (not shown) is maximum in order for the small volume of purge gas to carry out the entering nitrogen. As for the gas components, the contours of $\mathrm{CO}$ and $\mathrm{H}_{2}$ are quite nonlinear, but the composition in the operation window varies astonishingly little: The values are $\mathrm{CO} \approx 47-50 \%, \mathrm{CO}_{2} \approx 35-38 \%$ and $\mathrm{H}_{2} \approx 9.5-10.5 \%$. It is worth noting that this top gas composition corresponds well with the composition reported by Sahu et al. ${ }^{10)}$ who used similar input conditions for the oxygen blast furnace in their numerical study. The subfigure depicting the export gas energy shows that there is a region where the blast furnace top gas is not sufficient to heat the recycled top gas, and some coke oven gas (COG) is needed. This region (close to point $\square$ ) naturally corresponds to the highest values of $\beta$. As for the change in the specific emissions, the best point $\left(^{*}\right)$ is seen to lead to a decrease of about $100 \mathrm{~kg} / \mathrm{t}_{\mathrm{hm}}$ of $\mathrm{CO}_{2}$ (without $\mathrm{CO}_{2}$ storage) while the worst point $(\diamond)$ yields a $50 \mathrm{~kg} / \mathrm{t}_{\mathrm{hm}}$ increase.

As a final observation, we may note that with the given constraints it is almost impossible to operate the blast furnace with gas injection through the lower tuyeres, as the point $*$ lies practically on the $y$ axis $(\gamma=0 \%)$. Likewise, as the state approaches point $\diamond$ (where $\gamma \approx 48 \%$ ) only a small window exists for the operation. By contrast, at a share of $\gamma \approx 20-25 \%$ of shaft gas injection, the process shows the largest spectrum of feasible states. Therefore, it is expected that operation with some shaft gas but with a low flame temperature and intermediate top gas temperature would be a practical and less sensitive, but still an efficient, state of operation. If the coke rate is minimized, the operation window shrinks and the flame temperature decreases.

In order to illustrate the state of operation at the extreme points of the operation window, some central variables at the edges of the feasible region (cf. Fig. 2) have been depicted in Fig. 4, which shows specific flow rates, compositions and temperatures. The subfigures have been arranged so they spatially correspond to the layout of the extreme points in Fig. 2. For the state at the upper top vertex of the operation region (top left panel in Fig. 4) the top gas is insufficient $\left(-0.3 \mathrm{GJ} / \mathrm{t}_{\mathrm{hm}}\right)$ for the blast furnace, so COG is needed to heat the stoves. It may also be noted that the flows and compositions correspond quite well with those reported in Fig. 2 of the paper by Sahu et al., ${ }^{10)}$ where the main differences arise because of a higher rate of pulverized coal $\left(200 \mathrm{~kg} / \mathrm{t}_{\mathrm{hm}}\right)$ and blast moisture in the latter authors'
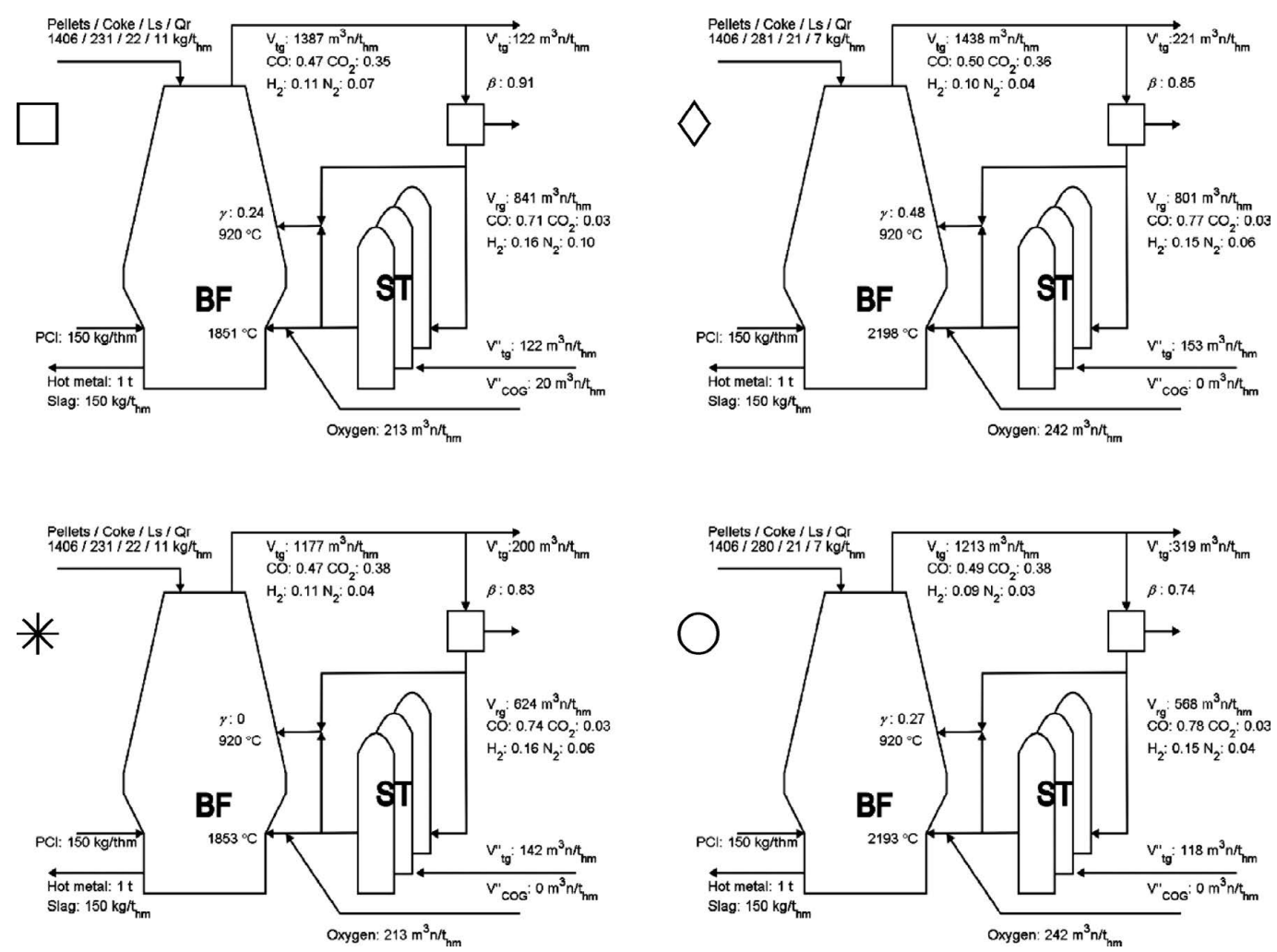

Fig. 4. Operational state for the four corners of the operation window depicted in Fig. 2. The placing of the subpanels corresponds to the layout of the vertices of the operation window in Fig. 2. 

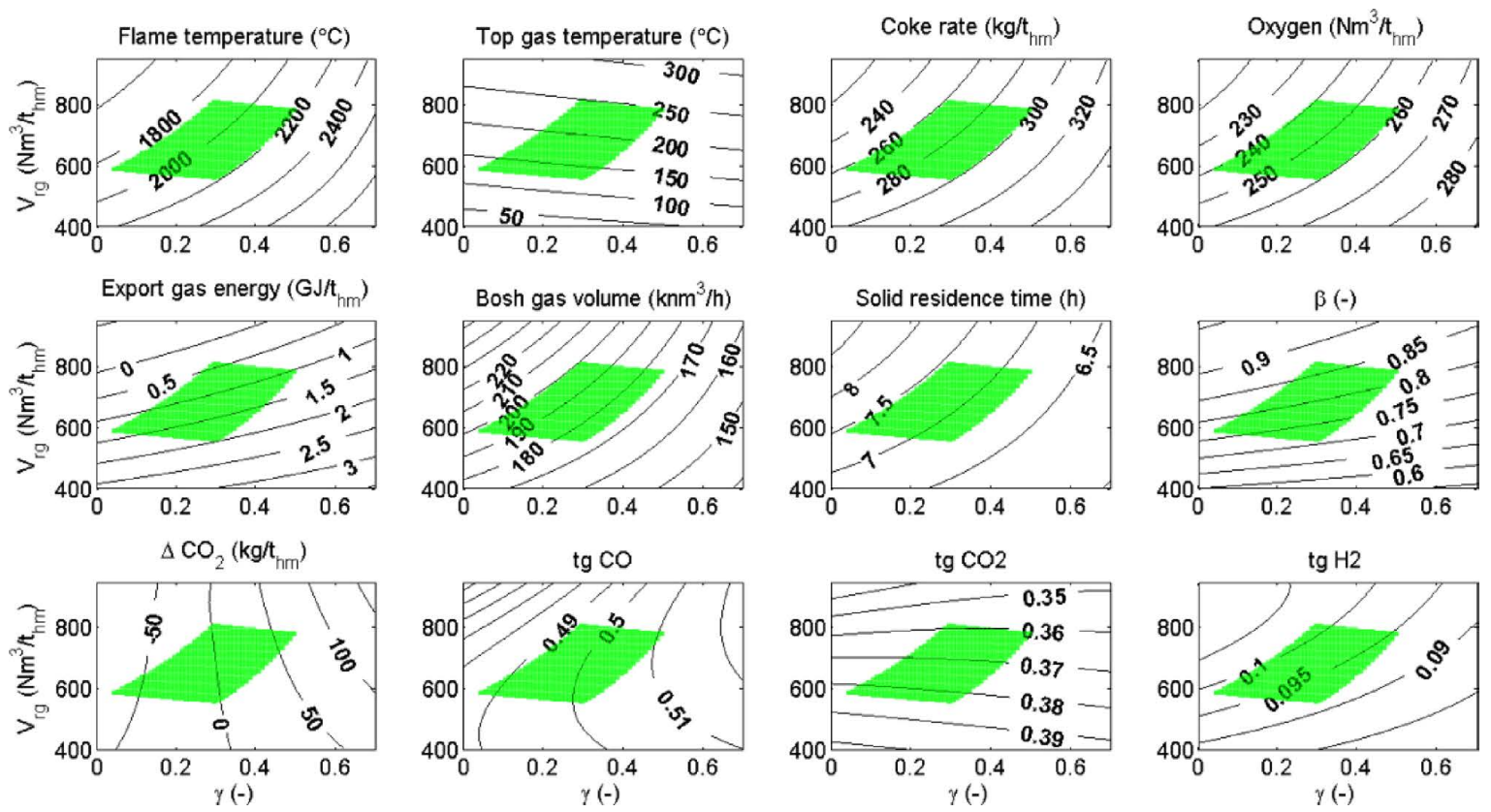

Fig. 5. Case 1: Blast temperature of $920^{\circ} \mathrm{C}$ at a PCI rate of $150 \mathrm{~kg} / \mathrm{t}_{\mathrm{hm}}$. Variables as defined in the caption of Fig. 3 . (Online version in color.)

example; this elevates the hydrogen levels in the gas flows.

\subsubsection{Blast Temperature $920^{\circ} \mathrm{C}$}

A simplified scheme is a one where no bypassing of the recycled gas is applied, and the gas is injected at the same temperature in the upper and lower tuyeres. Figure 5 illustrates the operation window for the case where the blast temperature is lowered to $920^{\circ} \mathrm{C}$, which influences the operation window by moving it right and downwards, i.e., towards higher shaft injection shares and also slightly lower amounts of recycled gas. It is no longer possible to operate the furnace with injection through the lower tuyeres only, as this would result in a too low flame temperature and/or too low top gas temperature. The clearly higher coke rate can also be seen together with the increased oxygen demand. The increase in the specific coke rate is $20-30 \mathrm{~kg} / \mathrm{t}_{\mathrm{hm}}$, which corresponds quite well to the changes a corresponding lowering of the blast temperature would bring about in conventional blast furnace operation. The maximum share of top gas recycling is now $\beta \approx 0.87$, while the gas composition does not change substantially from that of the first example. In all points of the feasible region, the top gas is sufficient for heating the recycled blast. For the emissions, the points in the feasible region with a shaft gas injection of less than $30 \%$ are seen to lead to lower $\mathrm{CO}_{2}$ emissions than in the reference case.

\subsubsection{PCI Rate $70 \mathrm{~kg} / \mathrm{t}_{\mathrm{hm}}$}

The influence on the operation window and the conditions of a lower pulverized coal rate is illustrated in Fig. 6, where the results for the case with a blast temperature of $1200^{\circ} \mathrm{C}$ but a PCI rate of $70 \mathrm{~kg} / \mathrm{t}_{\mathrm{hm}}$ are depicted. Compared to Fig. 3 , the operation window is seen to be smaller, and the maximum share of shaft gas injected decreases below 40\%: A $30-35 \mathrm{~kg} / \mathrm{t}_{\mathrm{hm}}$ higher coke rate, as well as about $150 \mathrm{Nm}^{3} / \mathrm{t}_{\mathrm{hm}}$ more recycled gas are seen to be required to compensate for the lower carbon and energy input with the pulverized coal. If the replacement ratio of pulverized coal versus coke is about 0.9 , this gives for the recycled gas a coke replacement ratio of $0.25 \mathrm{~kg} / \mathrm{Nm}^{3}$. This value compares favorably with the (marginal) replacement ratio of $0.24 \mathrm{~kg} / \mathrm{Nm}^{3}$ (of $\mathrm{CO}+\mathrm{H}_{2}$ ) reported by Hirsch et al. ${ }^{19)}$ The flame temperature is also affected: a higher amount of top gas has to be recycled to keep the same flame temperatures as in the first example (Fig. 3); this is natural as the injection of auxiliary reductants lowers the flame temperature. As more than $90 \%$ of the top gas is recycled, the top gas nitrogen content is higher (in some parts of the feasible region above 10\%) and the windows of all gas components are clearly smaller. In almost all feasible points (except point $\bigcirc$ ) COG is needed for heating the recycled gas. Compared to the reference furnace, the specific emissions increase by $100-250 \mathrm{~kg} / \mathrm{t}_{\mathrm{hm}}$, which is quite natural due to the lower PCI rate.

\subsubsection{Reserve Zone Temperature and Shaft Efficiency}

Some parameters of the model used to describe the operation of the blast furnace are user-specified, as theory does not provide direct guidelines on how the values should be selected. Two such parameters, which have been used when the model was adapted to mimic the true operation of the reference blast furnace, are the temperature of the thermal reserve zone and the shaft efficiency. For the former, results from simulation models and measurements by descending or fixed vertical probes (see, e.g., Taguchi et al. ${ }^{20)}$ ) suggest values in the range $900-1000^{\circ} \mathrm{C}$. For the shaft efficiency, which is a parameter representing the approach to chemical equilibrium of the wustite-iron reaction by $\mathrm{CO}$ and $\mathrm{H}_{2}$ in the reserve zone, the experience of the present authors and findings reported in the literature ${ }^{21)}$ suggest values in the range $85-95 \%$ for modern blast furnace operated with good raw materials.

In Fig. 7 the effect of a decrease in the reserve zone temperature from $920^{\circ} \mathrm{C}$ to $820^{\circ} \mathrm{C}$ is depicted. Compared to Fig. 3, the change is seen to lower the required coke 

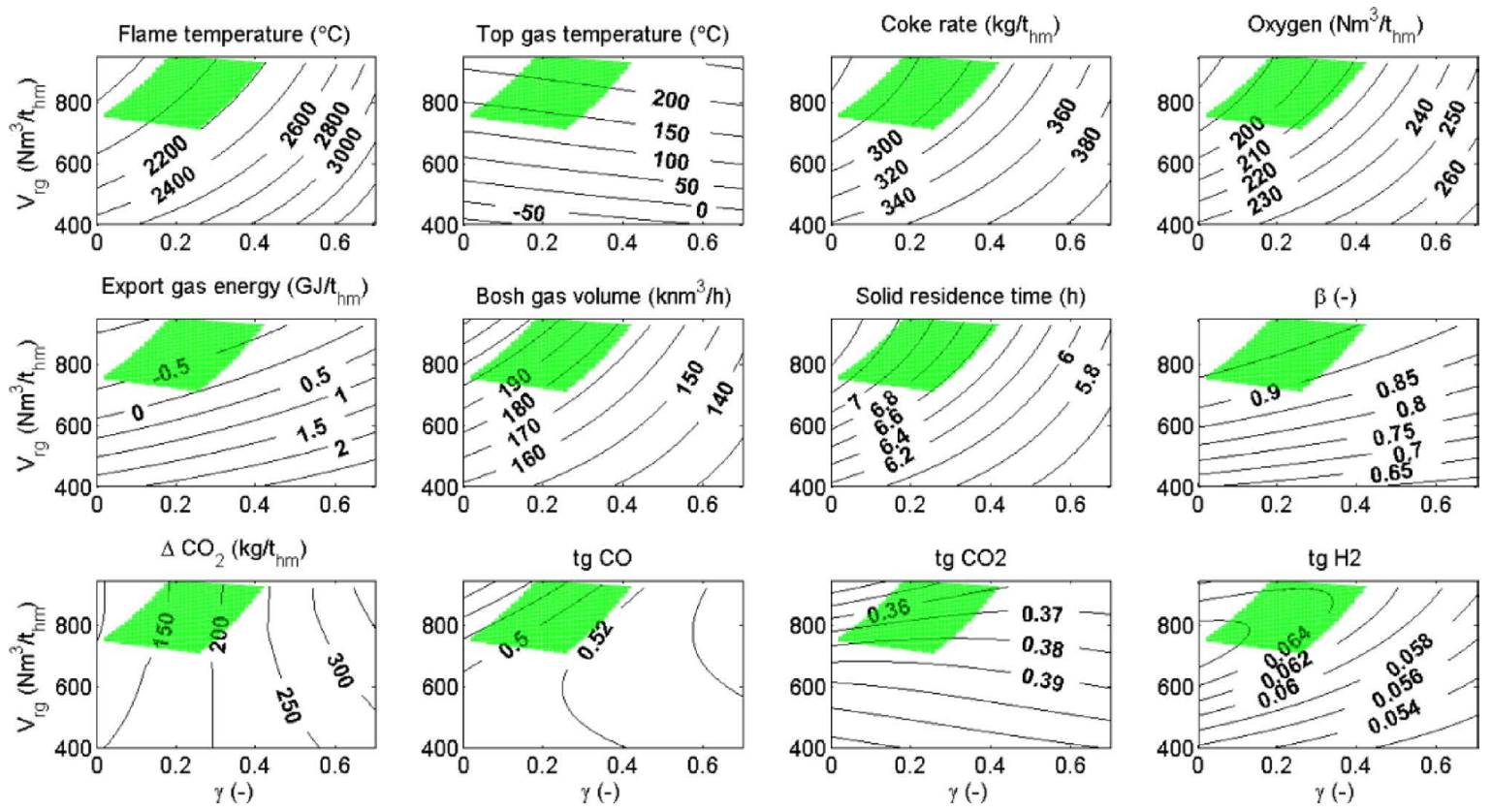

Fig. 6. Case 1: Pulverized coal rate of $70 \mathrm{~kg} / \mathrm{t}_{\mathrm{hm}}$ and blast temperature of $1200^{\circ} \mathrm{C}$. Variables as defined in the caption of Fig. 3. (Online version in color.)
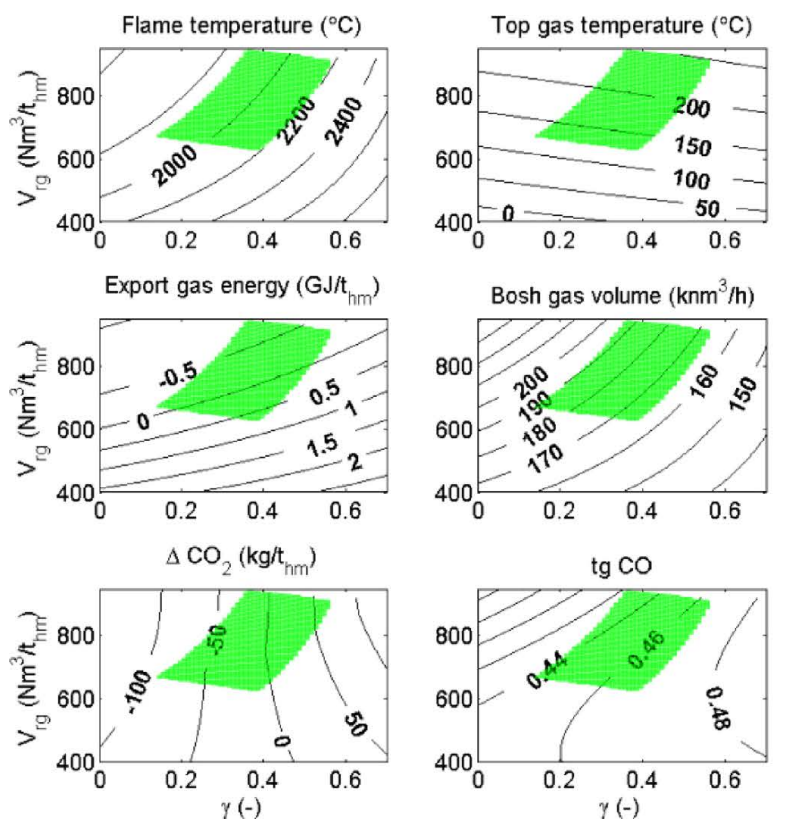
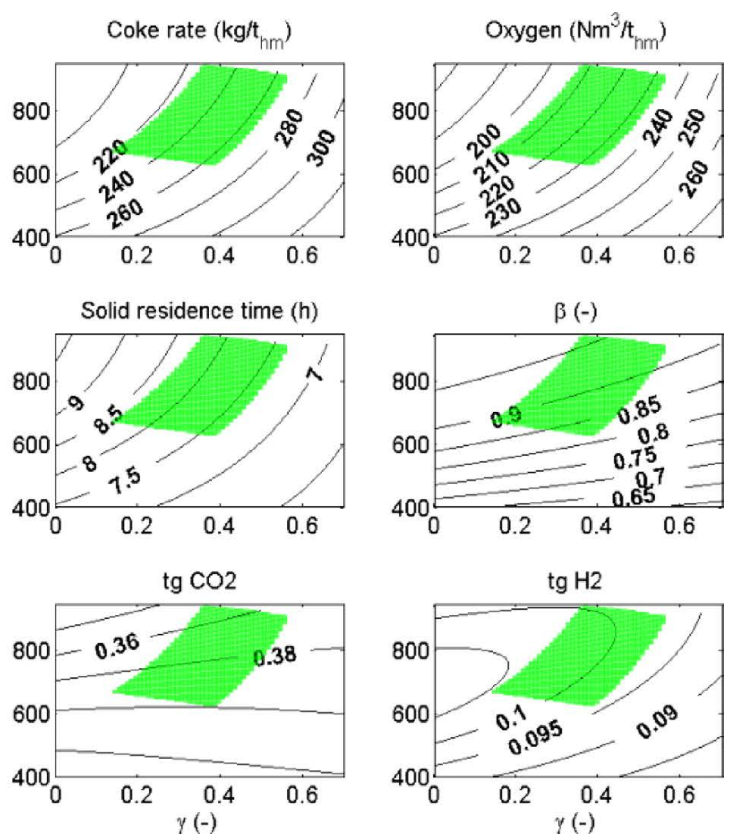

Fig. 7. Case 1: Thermal reserve zone temperature of $T_{\mathrm{rz}}=820^{\circ} \mathrm{C}$, blast temperature of $1200^{\circ} \mathrm{C}$ and $\mathrm{PCI}$ rate of $150 \mathrm{~kg} / \mathrm{t}_{\mathrm{hm}}$. Variables as defined in the caption of Fig. 3. (Online version in color.)

rate by about $10 \mathrm{~kg} / \mathrm{t}_{\mathrm{hm}}$ and it moves the operation window slightly to the right (towards higher shaft injection shares). It also lowers the top gas temperature, so somewhat higher amount of recycled top gas is needed to stay at or above the lower temperature boundary. In all, the effect on the other variables must be considered minor, so the reserve zone temperature can merely be considered a tuning parameter in the model. It should be noted that a change in the reserve zone temperature should be combined with a change in the shaft efficiency to yield a similar performance as the original model for the operation of the reference furnace.

Figure 8 shows how a decrease in the shaft efficiency from $90 \%$ to $85 \%$ influences the process: Slightly more coke and oxygen is required and a lower share of recycled gas is injected into the shaft to keep the BF operation within the feasible region. The top gas $\mathrm{CO}_{2}$ content is seen to be about 1 percentage point lower than in Fig. 3, while the $\mathrm{CO}$ content is about 2 percentage points higher, illustrating the mirror relation of the two variables when the furnace efficiency changes. The fact that the former variable changes less is due to the $\mathrm{CO}_{2}$ removal of the recycled gas, which introduces nonlinearities into the system.

In conclusion, relatively small changes in the model parameters do not fundamentally affect the findings concerning the operation window of the process. Therefore, the results do not critically depend on the specific values chosen in the present study but are of more general nature. 

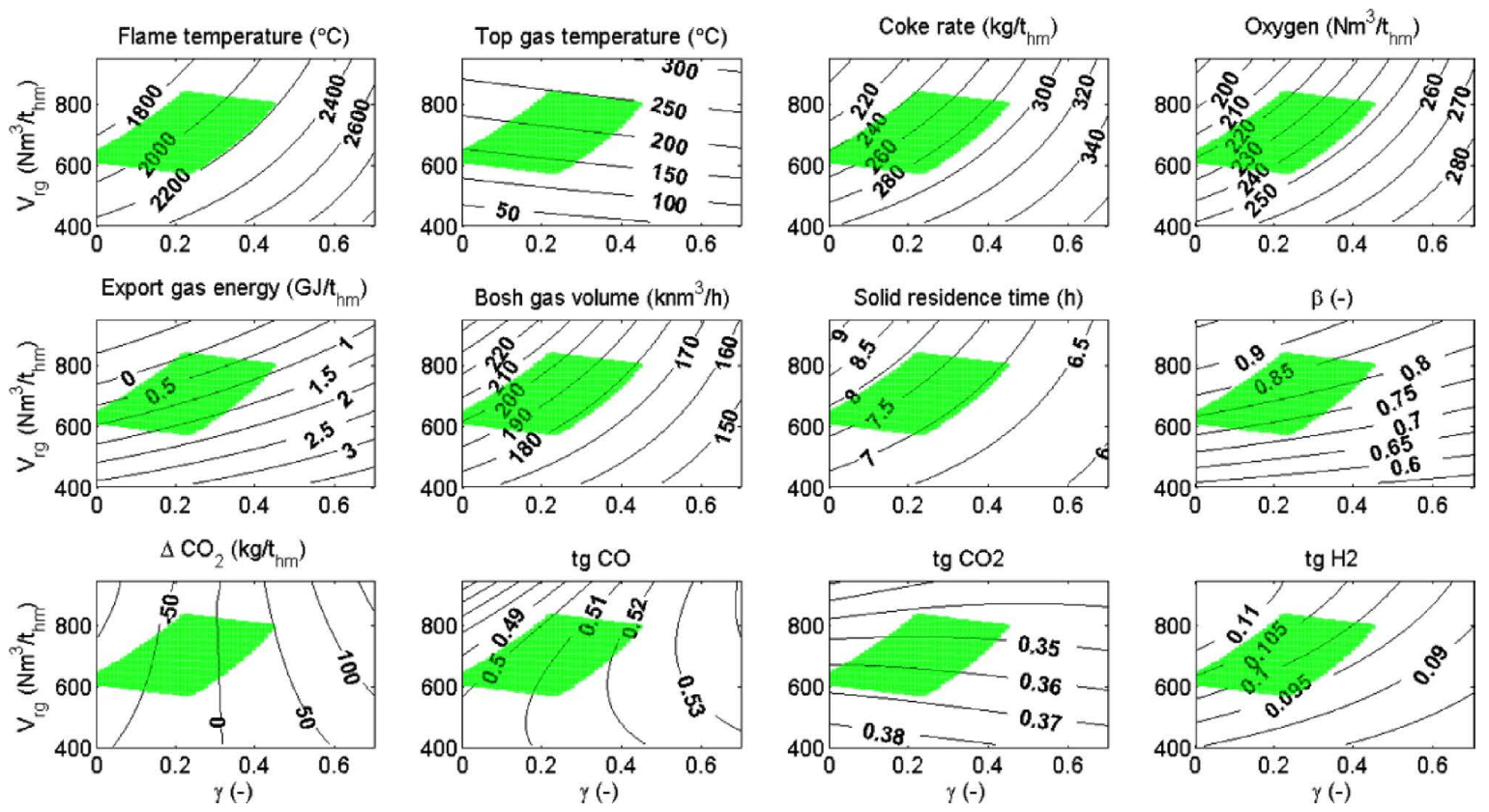

Fig. 8. Case 1: Shaft efficiency of $S E=85 \%$, blast temperature of $1200^{\circ} \mathrm{C}$ and PCI rate of $150 \mathrm{~kg} / \mathrm{t}_{\mathrm{hm}}$. Variables as defined in the caption of Fig. 3. (Online version in color.)
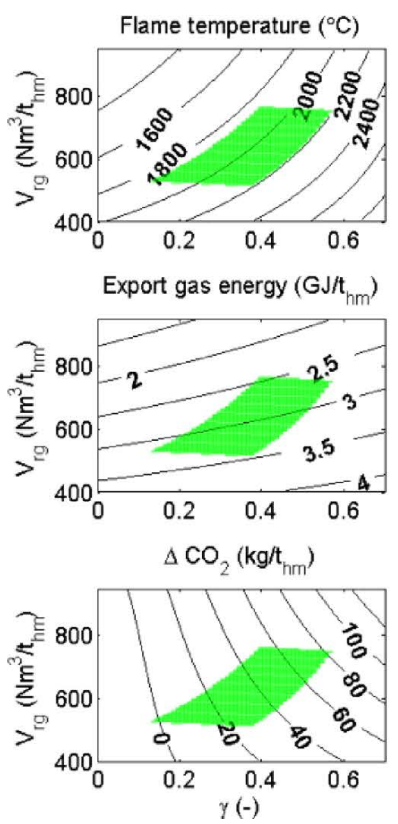
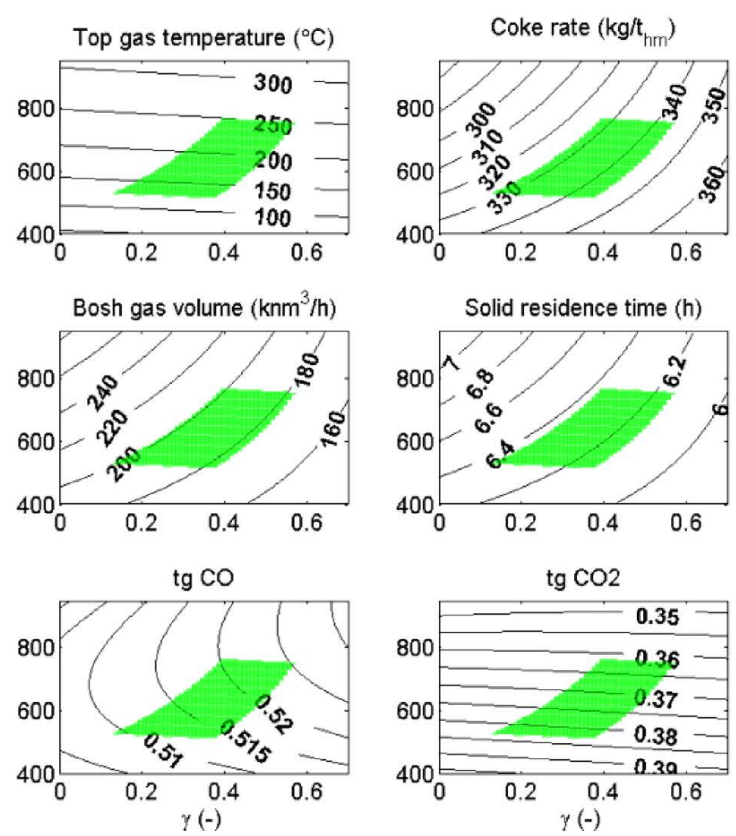
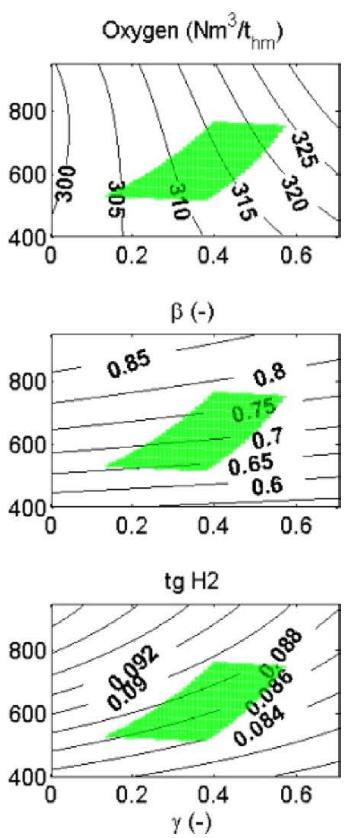

Fig. 9. Case 2: Recycled gas injected cold into the lower tuyeres and after partial combustion to $920^{\circ} \mathrm{C}$ into the shaft. PCI rate of $150 \mathrm{~kg} / \mathrm{t}_{\mathrm{hm}}$. Variables as defined in the caption of Fig. 3. (Online version in color.)

\subsection{Case 2}

This subsection presents results for Case 2, i.e., where the recycled gas is not heated in the stoves. Instead, it is injected cold in the lower tuyeres while its temperature is elevated to that of the reserve zone $\left(920^{\circ} \mathrm{C}\right)$ by partial combustion before it is injected in the shaft (cf. Fig. 1).

Figure 9 depicts the results for the case with pulverized coal injection of $150 \mathrm{~kg} / \mathrm{t}_{\mathrm{hm}}$. The general appearance of the operation window is similar to that of Fig. 3 in that the upper and lower boundaries are defined by the top gas temperature and the left and right boundaries by the flame temperature. However, the window is considerably smaller and shifted towards higher shaft injection rates: It is no longer possible to only inject the cold gas in the lower tuyeres.
This is partly due to the high PCI rate, which results in a low flame temperature. The coke rate is now considerably $\left(40-80 \mathrm{~kg} / \mathrm{t}_{\mathrm{hm}}\right)$ higher than in Fig. 3. Like for the other cases studied, with increased injection into the shaft the coke rate and the oxygen demand increase, simultaneously raising the flame temperature. Still, the operation point can be selected on the basis of the desired flame and top gas temperatures. It should be noted that the oxygen demand for Case 2 includes both the oxygen injected in the lower tuyeres and the oxygen used for partial combustion of the recycled gas before injection into the shaft. Since there are no hot stoves that would consume part of the available export gas, the energy available for downstream processes is increased significantly (to the range $2.5-3.5 \mathrm{GJ} / \mathrm{t}_{\mathrm{hm}}$ ) compared to the 


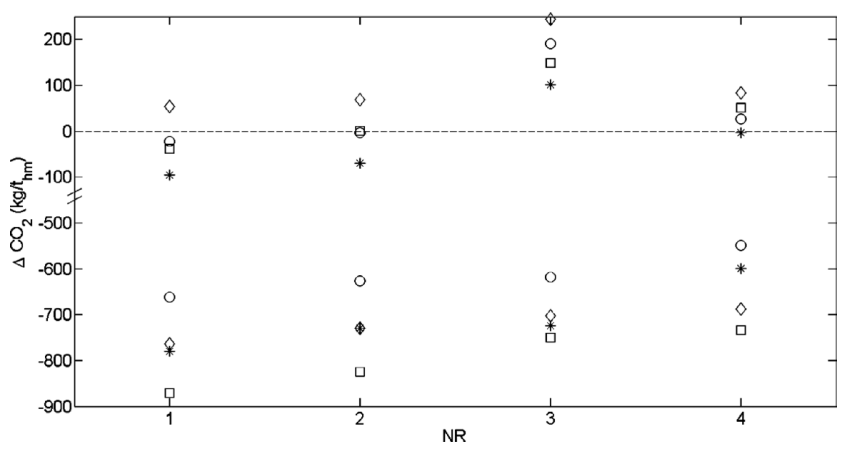

Fig. 10. Comparison of changes in $\mathrm{CO}_{2}$ emissions. Dashed line represents the reference case (normal BF without top gas recycling). The abscissa represents (1) Case 1, blast $1200^{\circ} \mathrm{C}$, (2) Case 1 , blast $920^{\circ} \mathrm{C}$, (3) Case 1, PCI $70 \mathrm{~kg} / \mathrm{t}_{\mathrm{hm}}$ and (4) Case 2, no gas preheating. Symbols correspond to the vertices of the operation window as depicted in Fig. 2. Upper and lower sets of points depict the change in $\mathrm{CO}_{2}$ emissions without and with storage of the stripped $\mathrm{CO}_{2}$. Note the discontinuous ordinate.

conditions for Case 1. Despite this, the $\mathrm{CO}_{2}$ emissions are higher than in the reference case in the whole feasible operation region (except in point ${ }^{*}$ ).

\section{4. $\mathrm{CO}_{2}$ Emissions}

The results reported show a clear decrease in the coke rate in all the different OBF scenarios studied for Case 1. However, due to the top gas recycling, less BF top gas (and sometimes also COG) is available for the downstream processes in the integrated steel plant. Naturally, the true potential in decreasing the emissions arises from the $\mathrm{CO}_{2}$ stripping from the top gas: If the stripped $\mathrm{CO}_{2}$ can be stored in a sustainable way, then the emissions can be decreased significantly. Figure 10 depicts the difference in $\mathrm{CO}_{2}$ emissions compared to the reference furnace for four of the simulated cases, i.e., those presented in Figs. 3, 4, 5 and 9 , depicting the conditions in the vertices of the feasible region. For the sake of simplicity, the $\mathrm{CO}_{2}$ storage was assumed to come at no extra emissions. In the comparison it is assumed that the other unit processes of the steel plant produce and use the same amount of gases and energy as in the reference case, so the only difference is in the BF, hot stoves and coke plant. From Fig. 10 it can be seen that if the removed $\mathrm{CO}_{2}$ is not stored (upper set of points) the emissions decrease in three vertices of Fig. $3(\mathrm{NR}=1)$ while they are distributed around the emissions of the reference state if the gas injection temperature is lowered to $920^{\circ} \mathrm{C}$ $(\mathrm{NR}=2$, cf. Fig. 4). For the two remaining case $(\mathrm{NR}=$ $3,4)$, operation in the feasible region increases the emissions with only one exception (point * in Fig. 9).

Comparing the changes in emission without or with storage of the stripped $\mathrm{CO}_{2}$ at the selected points of operation reveals other interesting findings. Overall, the emissions are lowered by $700-900 \mathrm{~kg} / \mathrm{t}_{\mathrm{hm}}$, but the order of the symbols are seen to change: This is due to the influence of the different top gas recycling degrees $(\beta)$ applied in the vertices, which results in different stripped amounts of $\mathrm{CO}_{2}$. Thus, the upper vertices (points $\square$ and $\diamond$ ) are seen to experience the largest reduction in emissions.

\section{Conclusions}

The operation conditions of the oxygen blast furnace with recycling of $\mathrm{CO}_{2}$-stripped top gas has been studied numerically, focusing on the amount of recycled top gas and the share of it that can be injected into the shaft. Some light has been shed to the behavior of this complex system by depicting the feasible region of operation of the furnace under some operation constraint, studying alternative ways of injecting the recycled gas (cold or heated). Also a case without the need for regenerative heat exchangers (hot stoves) has been studied, demonstrating the feasibility of operating the system with cold recycled gas. However, the simultaneous large increase in the coke rate $\left(40-80 \mathrm{~kg} / \mathrm{t}_{\mathrm{hm}}\right)$ probably makes this alternative economically infeasible despite an increased volume of export gas. The operation window has been found relatively small, which may be a challenge for the practical operation, particularly if the coke rate is minimized. A simplified study of the change in the emissions in the steel plant along with operating the oxygen blast furnace in different states was also made, showing that some of the alternatives did not reduce the $\mathrm{CO}_{2}$ emissions compared to a reference state of the furnace under normal operation. However, if the stripped $\mathrm{CO}_{2}$ can be stored, all alternatives within the feasible regions yielded reduced emissions.

In assessing the alternatives, the overall process economics should be considered, like done in Ref. 15) for the oxygen blast furnace with preheating and hearth tuyere injection of the recycled top gas, since recycling significant shares of the blast furnace top gas implies that less gas is available for other purposes in the plant. On the other hand, also the coke rate is lower than with the normal blast furnace operation, especially for the cases where the recycled gas is heated prior to injection, and the heating value of the export gas is improved due to high share of $\mathrm{CO}$ and much lower share of nitrogen than in normal BF operation. The $\mathrm{CO}_{2}$ removal makes it possible to considerably reduce the emissions to the environment from the process, which also affects the economy of the OBF operation through lower emission penalties.

\section{Acknowledgments}

The authors are grateful for financial support from the Academy of Finland within the SYMBIOSIS research project, and to TEKES and Finnish metals industry for support in the SIMP research program coordinated by FIMECC Ltd.

\section{REFERENCES}

1) J. van der Stel, G. Louwerse, D. Sert, A. Hirsch, N. Eklund and M. Pettersson: Ironmaking Steelmaking, 40 (2013), 483.

2) W. K. Lu and R. V. Kumar: ISS Trans., 5 (1984), 25.

3) M. Qin and N. Yang: Scand. J. Metall., 15 (1986), 138.

4) Y. Ohno, M. Matsuura, H. Mitsufuji and T. Furukawa: ISIJ Int., 32 (1992), 838.

5) M. A. Tseitlin, S. E. Lazutkin and G. M. Styopin: ISIJ Int., 34 (1994), 570 .

6) G. Q. Zuo and A. Hirsch: Rev. Met. C.I.T., 106 (2009), 387.

7) P. R. Austin, H. Nogami and J. Yagi: ISIJ Int., 38 (1998), 239.

8) R. Murai, M. Sato and T. Ariyama: ISIJ Int., 44 (2004), 2168.

9) H. Nogami, M. Chu and J. Yagi: Rev. Met. C.I.T., 102 (2005), 189.

$10)$ R. K. Sahu, S. K. Roy and P. K. Sen: Steel Res. Int., 86 (2015), 502, doi: 10.1002/srin.201400196.

11) M. Higuchi, M. Iizuka, K. Kuroda and T. Sumigama: Trans. Iron Steel Inst. Jpn., 15 (1975), 516. 
12) P. Wiklund, H. Saxén, J.-O. Wikström and M. Brämming: Proc. 60th Ironmaking Conf., ISS, Warrendale, PA, (2001), 721.

13) F. Pettersson and H. Saxén: ISIJ Int., 46 (2006), 1297.

14) A. Rist and N. Meysson: Rev. Metall., 61 (1964), 121.

15) H. Helle, M. Helle and H. Saxén: Chem. Eng. Sci., 66 (2011), 6470.

16) H. Helle, M. Helle, H. Saxén and F. Pettersson: ISIJ Int., 50 (2010), 931.

17) H. Helle, M. Helle, F. Pettersson and H. Saxén: ISIJ Int., 50 (2010), 1380

18) M. Peters and O. Schmöle: Stahl Eisen, 122 (2002), 43.

19) A. Hirsch, B. Korthas, J. Hülstrung, M. Grant, A. Berthelemot, D. Sert, F. Hanrot, G. Harp, J. Adam, J. van der Stel, M. Hattink, H. Jak, A. Veerman, O. Ansseau, G. Danloy, W. Küttner, N. Eklund, M. Pettersson, G. Zuo, B.-E. Sköld, L. Sundqvist, J.-P. Simoes, V. Dimastromatteo, M. Zagaria, A. Babich, R. Lin, A. Feiterna, A. Smith, T. Bürgler, A. Habermann, C. Feilmayr, C. Hitchinson and V. Ritz: New Blast Furnace Process, RFCS Final Report, EUR25085, European Commission, Publications Office of EU, Luxembourg, (2013).

20) S. Taguchi, H. Katayama, N. Tsuchiya, K. Okabe, K. Tanaka and K. Okumura: Stahl Eisen, 101 (1981), 1173.

21) M. Naito, K. Yamaguchi, Y. Inoue, A. Okamoto and T. Yamaguchi: Nippon Steel Tech. Rep., 94 (2006), 103.

\section{Appendix}

This appendix briefly outlines the procedure for solving the model equations. Even though the model consists of a set of nonlinear equations, an optimization problem was formulated to minimize the coke rate subject to the model equations. This guaranteed that the minimum feasible slag rate was obtained in the solution.

With reference to Fig. A1, the solution procedure of the equations is as follows: With given production rate, hot metal composition, PCI rate, recycled gas rate $\left(\beta \cdot \dot{V}_{\mathrm{tg}}\right)$ and share of shaft gas injection $(\gamma)$, iterate the coke rate, oxygen rate, top gas composition and quartzite rate so that the energy- and material balances for the elaboration zone (EZ) are satisfied. Simultaneously, the feed rate of lime/quartz (denoted as others in the figure) are determined to yield a slag basicity satisfying the desulfurization demand of the hot metal and the raceway adiabatic flame temperature is calculated. The recycled gas injected into the shaft determines the composition of the gas entering the preparation zone (PZ) for which an approach to equilibrium is imposed (through the shaft efficiency parameter, SE) giving the utilization degrees of $\mathrm{CO}$ and $\mathrm{H} 2\left(\eta_{\mathrm{CO}}^{\mathrm{EZ}}, \eta_{\mathrm{H}_{2}}^{\mathrm{EZ}}\right)$. Solving the PZ energy balance equation gives the top gas temperature.

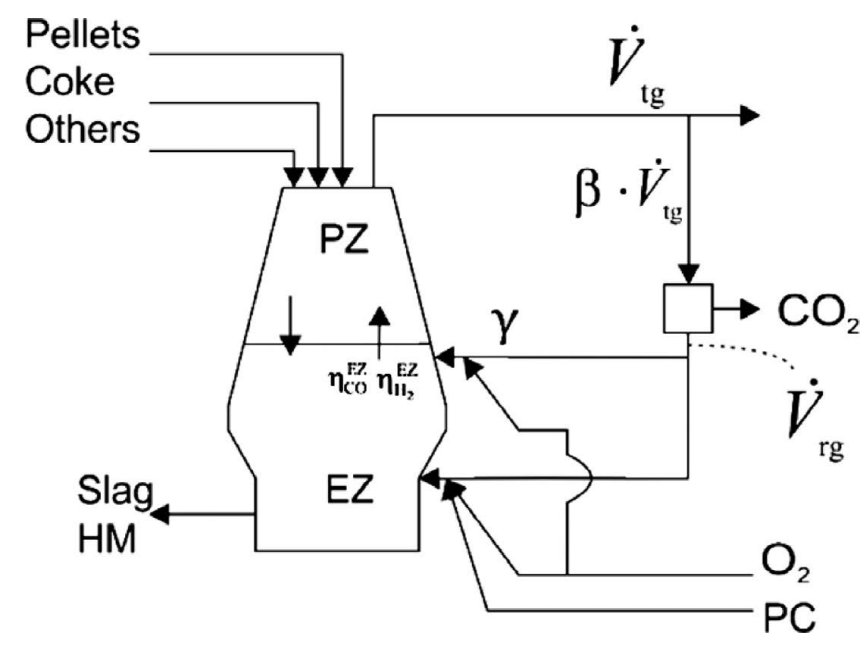

Fig. A1. Schematic division of the process and central flows in the model. 